\title{
Gene delivery to the hypoglossal motor system: preclinical studies and translational potential
}

\author{
Brendan M. Doyle ${ }^{1,2,3,4} \cdot$ Michele L. Singer ${ }^{1,2,3,4} \cdot$ Thomaz Fleury-Curado ${ }^{5,6} \cdot$ Sabhya Rana $\mathbb{1}^{1,2,4}$. \\ Ethan S. Benevides ${ }^{1,2,3,4} \cdot$ Barry J. Byrne ${ }^{5}$ Vsevolod Y. Polotsky ${ }^{5,6}$ David D. Fuller $\mathbb{B}^{1,2,4}$
}

Received: 4 August 2020 / Revised: 16 December 2020 / Accepted: 15 January 2021 / Published online: 11 February 2021

(c) The Author(s) 2021. This article is published with open access

\begin{abstract}
Dysfunction and/or reduced activity in the tongue muscles contributes to conditions such as dysphagia, dysarthria, and sleep disordered breathing. Current treatments are often inadequate, and the tongue is a readily accessible target for therapeutic gene delivery. In this regard, gene therapy specifically targeting the tongue motor system offers two general strategies for treating lingual disorders. First, correcting tongue myofiber and/or hypoglossal (XII) motoneuron pathology in genetic neuromuscular disorders may be readily achieved by intralingual delivery of viral vectors. The retrograde movement of viral vectors such as adeno-associated virus (AAV) enables targeted distribution to XII motoneurons via intralingual viral delivery. Second, conditions with impaired or reduced tongue muscle activation can potentially be treated using viral-driven chemo- or optogenetic approaches to activate or inhibit XII motoneurons and/or tongue myofibers. Further considerations that are highly relevant to lingual gene therapy include (1) the diversity of the motoneurons which control the tongue, (2) the patterns of XII nerve branching, and (3) the complexity of tongue muscle anatomy and biomechanics. Preclinical studies show considerable promise for lingual directed gene therapy in neuromuscular disease, but the potential of such approaches is largely untapped.
\end{abstract}

These authors contributed equally: Brendan M. Doyle, Michele L. Singer

David D. Fuller

ddf@phhp.ufl.edu

1 Department of Physical Therapy, University of Florida, Gainesville, FL, USA

2 McKnight Brain Institute, University of Florida, Gainesville, FL, USA

3 Rehabilitation Science PhD Program, University of Florida, Gainesville, FL, USA

4 Breathing Research and Therapeutics Center, University of Florida, Gainesville, FL, USA

5 Department of Pediatrics and Powell Gene Therapy Center, University of Florida, Gainesville, FL, USA

6 Division of Pulmonary and Critical Care Medicine, Department of Medicine, Johns Hopkins University School of Medicine, Baltimore, MD, USA

\section{Introduction}

The lingual or hypoglossal (XII) motor system is comprised of the intrinsic and extrinsic muscles of the tongue and the motoneurons which innervate them. Dysfunction and/or reduced output of the XII motor system can contribute to conditions such as dysphagia, dysarthria, and sleep disordered breathing. The fundamental thesis of this article is that gene therapy targeting the XII motor system has therapeutic potential for a variety of lingual-related disorders, but this potential is largely untapped. Gene therapy targeting the XII motor system offers two general strategies for treating lingual disorders. First, correcting tongue and/or XII motoneuron pathology in genetic neuromuscular disorders may be readily achieved by lingual directed delivery of viral vectors. The retrograde movement of vectors such as adeno-associated virus (AAV) enables targeted gene delivery to XII motoneurons following lingual delivery. Second, conditions with impaired or reduced tongue muscle activation can potentially be treated using viral-driven chemo- or optogenetic approaches to activate XII motoneurons and/or tongue myofibers. 


\section{Tongue muscles and motoneurons}

The tongue is comprised of eight skeletal muscles that perform mechanically complex movements and cause threedimensional changes in tongue shape [1]. The complex lingual muscle architecture makes it difficult to precisely identify the biomechanical impact of individual muscles, but lingual muscles work in concert to execute tongue movements during behaviors such as eating, breathing, and oral communication [2].

The four intrinsic tongue muscles consist of myofibers completely contained within the body of the tongue and their contraction alters tongue shape. The complexity of the intrinsic musculature is highlighted by the concept of the tongue as a "muscular hydrostat". In this regard, the tongue can be thought of as a cylindrical structure with a constant volume, and small decreases in diameter can produce significant increases in length [3]. The four extrinsic tongue muscles originate from bony attachment sites or connective tissues of the hyoid bone, mandible, and styloid process [4-6]. Extrinsic muscle contraction can protrude or retract the tongue as well as depress the tongue base. Table 1 summarizes the innervation and mechanical actions of the tongue muscles based on prior publications [7-10].

Tongue innervation via the XII nerve undergoes extensive branching as the main trunk approaches the body of the tongue $[4,11,12]$. Humans and rodents have a distinct medial XII branch which innervates the primary protrusor muscle, the genioglossus [7]. The primary retractor muscles, the hyo- and styloglossus, are innervated by a lateral XII branch with variable presentation in humans [7]. The medial and lateral XII branches could be particularly useful in the context of targeted gene delivery studies to protrusor or retractor muscles.

The XII motor nucleus is a somatotopically organized, longitudinal column in the dorsal medulla. Generally, XII motoneurons located dorsally innervate retractor muscles, whereas ventrally located motoneurons innervate protrusors [6]. The ventral nucleus is further subdivided with medial cells innervating intrinsic protrusor muscles and lateral cells innervating extrinsic protrusors [13]. Within the dorsal nucleus, cells innervating intrinsic retractor muscles are located dorsomedially, and cells projecting to extrinsic retractors are located laterally [14]. The somatotopic segregation of XII motoneurons into functional groups also appears to extend to their biophysical properties. A recent investigation found that motoneurons of intrinsic tongue muscles had greater resting membrane potentials (i.e., more depolarized) as compared to genioglossus motoneurons [15].

\section{Tongue motor impairments}

Coordinated tongue movements enable manipulation and posterior transport of a food bolus. Accordingly, dysphagia (disordered swallow function) is often present when lingual function is compromised [16-18]. Consequences include aspiration, pneumonia, airway obstruction, dehydration, weight loss, and malnutrition [19, 20]. Motor speech impairments such as dysarthria have been associated with diminished strength, endurance, and/or motor activation of lingual muscles [21-23]. The consequences of dysarthria extend beyond impaired communication and can considerably reduce overall quality of life [24-26]. Therapeutic

Table 1 Innervation and mechanical actions of the intrinsic and extrinsic tongue muscles.

\begin{tabular}{|c|c|c|c|}
\hline Muscle & Motoneurons & Nerve & Mechanical action \\
\hline $\begin{array}{l}\text { Genioglossus } \\
\text { (Extrinsic) }\end{array}$ & $\begin{array}{l}\text { Lateral and centrolateral aspects } \\
\text { of the ventral compartment }\end{array}$ & XII, Medial branch & $\begin{array}{l}\text { Tongue protrusion (posterior fibers), tongue } \\
\text { retraction (anterior fibers), and depress } \\
\text { tongue body }\end{array}$ \\
\hline $\begin{array}{r}\text { Hyoglossus } \\
\text { (Extrinsic) }\end{array}$ & $\begin{array}{l}\text { Lateral aspect of the dorsal } \\
\text { compartment }\end{array}$ & XII, Lateral branch & $\begin{array}{l}\text { Depresses and retracts tongue body, } \\
\text { elevates hyoid bone }\end{array}$ \\
\hline $\begin{array}{l}\text { Palatoglossus } \\
\text { (Extrinsic) }\end{array}$ & Nucleus ambiguus & $\mathrm{X}$, Pharyngeal branch & $\begin{array}{l}\text { Posterior tongue elevation, grooves the } \\
\text { tongue, and depresses soft palate }\end{array}$ \\
\hline $\begin{array}{l}\text { Styloglossus } \\
\text { (Extrinsic) }\end{array}$ & $\begin{array}{l}\text { Lateral aspect of the dorsal } \\
\text { compartment }\end{array}$ & XII, Lateral branch & Elevation and retraction of tongue \\
\hline $\begin{array}{l}\text { Inferior } \\
\text { longitudinal } \\
\text { (Intrinsic) }\end{array}$ & $\begin{array}{l}\text { Dorsomedial aspect of the dorsal } \\
\text { compartment }\end{array}$ & XII, Medial and lateral branches & $\begin{array}{l}\text { Depress tongue tip, shortens tongue } \\
\text { (retraction) }\end{array}$ \\
\hline $\begin{array}{l}\text { Superior } \\
\text { longitudinal } \\
\text { (Intrinsic) }\end{array}$ & $\begin{array}{l}\text { Dorsomedial aspect of the dorsal } \\
\text { compartment }\end{array}$ & XII, Lateral branch & $\begin{array}{l}\text { Elevates tongue tip, shortens tongue } \\
\text { (retraction) }\end{array}$ \\
\hline $\begin{array}{l}\text { Transversus } \\
\text { (Intrinsic) }\end{array}$ & $\begin{array}{l}\text { Medial aspect of ventral } \\
\text { compartment }\end{array}$ & XII, Medial branch & Narrows and elongates tongue (protrusion) \\
\hline $\begin{array}{l}\text { Verticalis } \\
\text { (Intrinsic) }\end{array}$ & $\begin{array}{l}\text { Medial aspect of ventral } \\
\text { compartment }\end{array}$ & XII, Medial branch & Flattens and elongates tongue (protrusion) \\
\hline
\end{tabular}




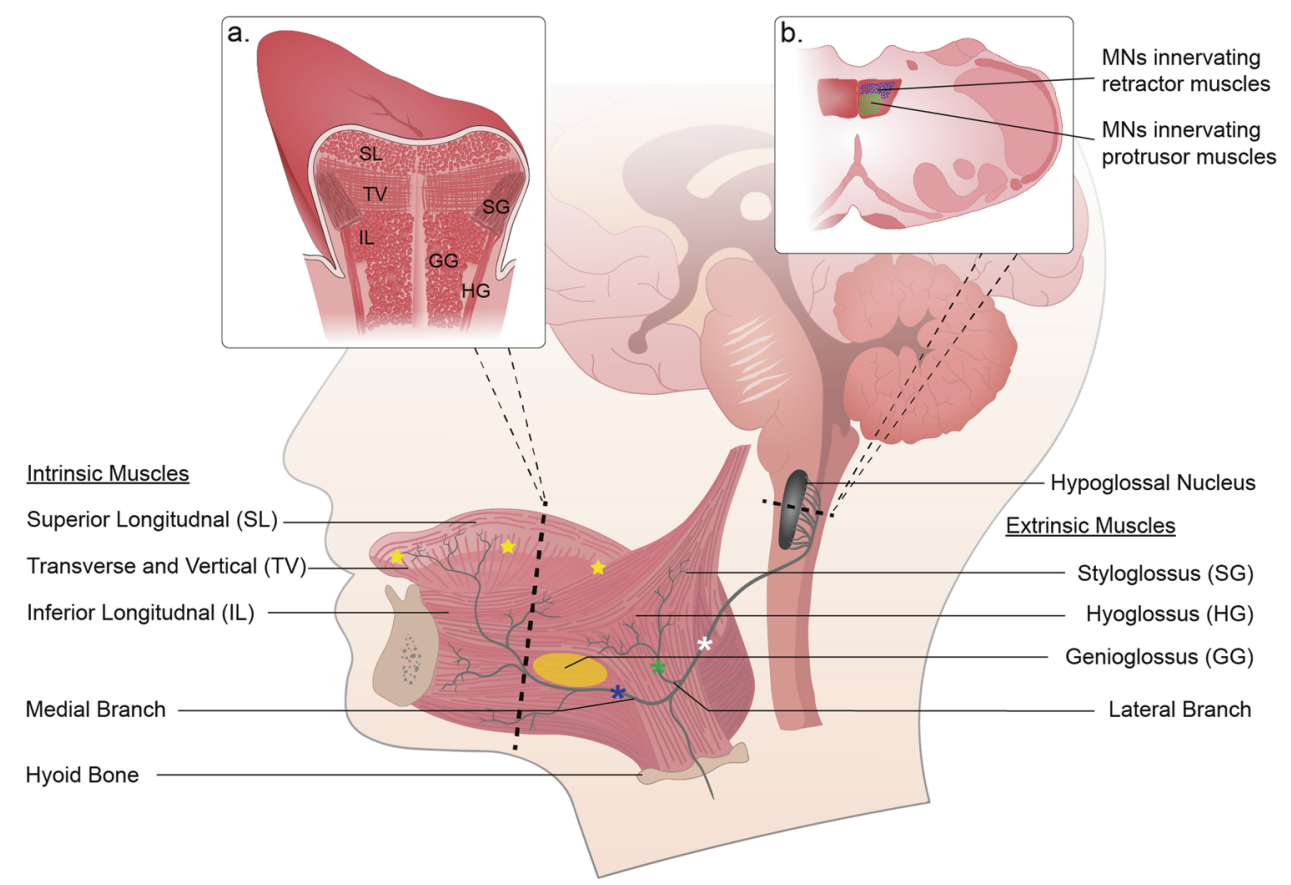

Fig. 1 Schematic diagram of the hypoglossal (XII) motor system emphasizing potential sites for viral injection. The XII motor nucleus innervates the tongue via cranial nerve XII. The intrinsic muscles form the body of the tongue and the extrinsic muscles insert into the body of the tongue. The main XII nerve trunk bifurcates with the lateral branch innervating extrinsic retractors and the medial branch innervating extrinsic protrusors. Both branches also innervate intrinsic tongue muscles. The star symbols show potential injection sites for targeted gene delivery directly to the main body of the tongue. The yellow oval on the

approaches to address lingual deficits include diet modification, compensatory postural changes and/or environmental adjustments [27, 28]. Other treatments include mechanical or thermal stimulation, oromotor strengthening exercises, and electrical stimulation [25, 29-31]. These treatments represent strategies to help improve or compensate for lingual motor dysfunction, but they do not address the underlying pathology. In this regard, gene therapy may represent a novel therapeutic option, but there has been limited work on this topic [32].

Obstructive sleep apnea (OSA) is present in $10 \%$ of the population and lingual mechanisms figure prominently in the etiology. Specifically, sleep-related reductions of tongue muscle activation contribute to or cause upper airway narrowing or collapse. Of the tongue muscles, the genioglossus has been particularly emphasized, beginning with the seminal work of Remmers who hypothesized that reduced activity during sleep led to airway obstruction [33]. Decreases in genioglossus muscle activity are normal during sleep, but are greater in OSA patients [34]. Mechanistically, decreases in tongue muscle activity during sleep appear to reflect decreased noradrenergic input to XII motoneurons during NREM [35] and increased muscarinic cholinergic input during REM [36]. genioglossus represents a potential site of viral injection if the goal is selective activation of this muscle (or associated XII motoneurons) using opto- or chemogenetics. Potential sites for direct XII nerve injection include the medial branch (blue asterisk), lateral branch (green asterisk) and main trunk (white asterisk). Direct stereotaxic viral delivery to the XII nucleus is also possible in preclinical studies. Inset panels: a coronal section of the tongue illustrating organization of extrinsic and intrinsic muscles; b horizontal section of the medulla highlighting somatotopic organization of XII motoneurons.

Treatments for OSA include surgical intervention and chronic positive airway pressure. In addition, since decreased tongue muscle activity leads to OSA, much research has focused on stimulating XII motor output during sleep. Direct stimulation of the XII nerve [37] can decrease pharyngeal collapsibility [38], relieves airflow obstruction [39], and can decrease OSA severity [40]. Pharmacological treatments are limited, but clinical trials targeting the noradrenergic and cholinergic systems show promise [41-43] and may suggest targets for gene therapy. Desipramine, a norepinephrine reuptake inhibitor, can reduce OSA severity in some patients [43]. The combination of atomoxetine (a norepinephrine reuptake inhibitor) and oxybutynin (an antimuscarinic drug) is more effective [42]. Thus, treatments that increase tongue muscle activation can be effective in treating OSA. Initial work in animal models (see next section) suggests that gene therapy strategies to excite XII motoneurons may also be effective [44].

\section{Targeted gene delivery to the XII motor system using AAV}

The accessibility of the tongue (Fig. 1) and foundational knowledge of its innervation and basic biomechanics 
(Table 1) make it amenable to targeted gene delivery using viral vectors. Thus, gene delivery to the tongue and XII motoneurons has utility in preclinical studies of respiratory and/or lingual motor control, as well as potential for gene therapy for lingual-related disorders. In regard to therapeutic applications, we suggest two primary strategies. First, in cases of genetic neuromuscular disorders with lingual pathology, targeted viral delivery to the tongue and/ or XII motoneurons may "correct" pathology and improve XII motor function. Second, in cases where activation of the tongue muscles is inadequate, direct excitation of tongue myofibers and/or XII motoneurons could be achieved using viral-driven opto- or chemogenetic strategies. Both approaches require efficient delivery of viral vectors to the XII motor system, and this is reviewed next.

\section{Targeting the tongue via intralingual viral delivery}

Intralingual vector delivery effectively drives gene and protein expression in the tongue [32, 45-47] and can reverse tongue muscle histopathology in neuromuscular disease [45-47]. Pompe disease is a neuromuscular disorder associated with mutations in a single gene (acid alpha glucosidase or GAA), macroglossia, dysphagia, and dysarthria [48]. Thus, a murine Pompe model $\left(\mathrm{Gaa}^{-/-}\right)$was used to determine if intralingual AAV injections could produce sustained GAA expression with reversal of the tongue myofiber histopathology [45]. A single injection of AAV9DES-GAA to the tongue base was highly effective in driving transgene (GAA) expression localized to the posterior tongue. Tissues harvested 4 months after intralingual AAV9 therapy showed robust GAA expression with concomitant reductions in glycogen accumulation. The AAV injection was insufficient to drive transgene expression across the anterior-posterior length of the tongue, but this could be circumvented through multiple injections targeting anterior and posterior regions.

Viral vectors can also drive gene expression in lingual taste cells via direct injection into the tongue submucosa $[49,50]$. Several serotypes of AAV have been screened for this purpose including AAV1, 2, 5, 6, as well as a lentiviral vector; however, none were effective at driving gene expression in taste cells. However, a synthetic AAV serotype known as AAV-DJ was highly effective at driving gene expression in all functional taste cell types [49, 50]. The AAV-DJ has a hybrid capsid created from 8 AAV serotypes via DNA family shuffling technology, and demonstrates higher infectivity rates across a broad range of cells and tissue types [51]. Gene expression was also observed in nongustatory epithelial cells as well as the underlying mesenchymal and lingual muscle cells. These studies illustrate that beyond targeting lingual motor disorders, tongue gene transfer may have utility in elucidating the roles of specific proteins in taste cell development and gustation [49, 50].

The local (e.g., site of intramuscular injection) and/or systemic immune response is always a potential concern with viral gene transfer [52]. The host immune response can reduce or even negate the treatment through targeting of viral particles and/or elimination of cells expressing the transgene. In our studies of single injections of AAV9 and AAV2 to the murine tongue $[45,46,53]$ we have not observed a significant local immune response (i.e., at or near the site of AAV delivery). Further, following tongue injection with AAV9, persistent XII motoneuron transgene expression was observed at the longest time point we evaluated (1 year) following the AAV delivery [46]; longer time intervals have not been assessed in the lingual system. Attention to the immune response is of particular importance when translating AAV therapies from preclinical animal models to human application. Antibodies to AAV can be found in many humans due to environmental exposure to AAV [54], and the murine immune response to AAV is different than in humans [55]. Nevertheless, transgene expression has been confirmed up to 5 years following intramuscular AAV injection in humans [56], thereby demonstrating the potential of this approach for long-term correction of physiological deficits. Immune management is a major area of emphasis in clinical trials of $\mathrm{AAV}$, and the reader is directed to recent reviews of this topic $[57,58]$

The immune response will be a particular concern if multiple AAV injections are separated in time, and should be carefully evaluated and monitored in any therapeutic study of AAV delivery [57, 59]. However, if multiple intralingual viral injections are delivered during the same acute surgical session (e.g., to better infect the entire tongue), this should circumvent the immune response that would likely accompany AAV injections separated by days to weeks.

Another challenge of lingual viral injections targeting specific tongue muscles is the complex architecture of the tongue (Fig. 1). This makes focal delivery to a particular intrinsic or extrinsic tongue muscle technically difficult, such as targeting the primary tongue protrusor the genioglossus. Targeting a specific lingual muscle is not likely to be a concern in therapeutic studies of lingual muscle function in neuromuscular disorders such as Pompe disease [45], but will be a concern in studies aimed at delivering light or chemically-activated proteins to selective muscles (see next section). Relative specificity of tongue muscle transduction is possible in smaller species with low injection volumes [44], and the accuracy of lingual viral injections should improve as the size of the tongue increases, making it easier to delivery small injection volumes to specific muscles. 

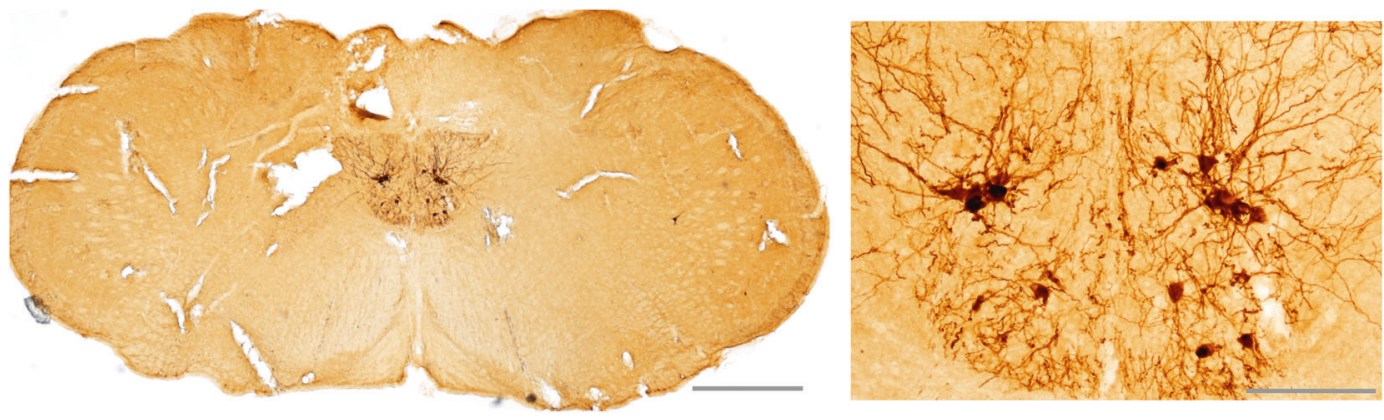

Fig. 2 Bilateral XII motoneuron transgene expression following intralingual injection of AAV9-GFP. The right panel shows a higher power view of both XII nuclei. XII motoneuron staining can be seen to extend beyond the soma and with extensive axonal/dendritic branching. Scale bars: left panel, $500 \mu \mathrm{m}$; right panel, $100 \mu \mathrm{m}$.

\section{Targeting XII motoneurons using intralingual AAV delivery}

Direct skeletal muscle injection of viral vectors followed by retrograde axonal transport provides a means to target gene delivery directly to a specific motoneuron pool. Retrograde targeting of motoneurons by AAV was first shown by Kasper et al. [60] and multiple AAV serotypes, including 1, $2,5,6,7,8$, and 9 can show retrograde movement in select neural circuits [60-66]. Several studies confirm that intralingual delivery of AAV (serotypes 1 and 9) can drive longterm gene expression in XII motoneurons [45-47, 53], and targeting genioglossus motoneurons can be achieved with reasonable specificity [44]. The first report was from Elmallah et al. who delivered AAV9-CBA-GFP to the base of the tongue in adult mice. Expression of GFP was present at 8 weeks post-injection in an average of $234 \pm 43$ XII motoneurons [53]. The AAV9 results were compared to a highly efficient retrograde tracer (cholera toxin- $\beta$ ) which labeled approximately fourfold more XII neurons. The total number of XII motoneurons in an adult mouse is between 900 and 1600 [67, 68], and thus the AAV9 method infected between 15 and $25 \%$ of the motoneuron pool. This is consistent with a subsequent report indicating that intralingual AAV9 can infect $32 \%$ of the XII motoneuron pool [44]. Direct comparisons of AAV1 vs. AAV9 indicate that AAV9 is considerably more effective at retrograde movement following intralingual delivery [46]. More recent work raises the possibility of XII motoneuron "cross correction" via lingual AAV9 delivery [45]. Pompe $\left(\mathrm{Gaa}^{-1-}\right)$ mice received an intralingual injection of AAV9 which encoded a modified GAA protein designed for improved cellular trafficking. The modified GAA was detected in $~ 200 \%$ more XII motoneurons as compared to treatment with AAV9 encoding a "normal" GAA protein. Cross correction could occur if GAA secreted from one AAV9 transduced XII motoneuron moves via receptor mediated uptake into adjacent motoneurons and is subsequently trafficked to lysosomes.
Intralingual AAV therapy also shows promise in treating amyotrophic lateral sclerosis (ALS). In the SOD $1^{\mathrm{G} 93 \mathrm{~A}}$ mouse model of ALS, a single intralingual treatment with AAV driving expression of microRNA targeting the superoxide dismutase 1 (SOD1) gene (AAVrh10-H1-miR ${ }^{\mathrm{SOD} 1}$ ) dramatically reduced SOD1 mRNA expression in the tongue, and caused a small $(\sim 1 \mathrm{wk})$ but statistically significant increase in lifespan in females [32]. The lingual treatment also improved aspects of breathing function but did not impact swallow as studied using videofluoroscopy. Another study in the same ALS mouse model found that lingual treatment with AAVrh10-H1-miR ${ }^{\mathrm{SOD} 1}$ preserved the integrity of tongue neuromuscular junctions, but did not impact survival of XII motoneurons [47].

As an example, Fig. 2 shows XII motoneuron gene expression following direct intralingual AAV9 delivery. This example is from our laboratory using adult mice and shows robust XII motoneuron transgene expression 12 weeks following delivery of $20 \mu \mathrm{l}$ of AAV9-CBA-GFP to the base of the tongue. To our knowledge, there is no evidence that the virus first infects muscle cells before moving across the neuromuscular junction. Rather, viral transport is a multistep process that begins with binding of the capsid to a cell surface receptor [69]. The initial uptake requires cell surface glycan receptors that vary by serotype [70, 71]. Once in the cell, AAV9 is first trafficked into nonmotile endosomes, then exocytic vesicles and a retrograde-directed late endosome/ lysosome compartment [72]. Endosomal transport is driven by cytoplasmic dynein and requires Rab7 function [72]. Similar mechanisms occur in serotypes AAV1 and AAV8 [66].

Several methods could potentially increase the relative number of transduced XII motoneurons following tongue delivery of viral vectors. For example, myelin is a potential barrier for uptake of the AAV capsid into the nerve terminal, and transient demyelination via ethidium bromide can increase retrograde transduction efficiency up to sixfold in large diameter sensory neurons [73]. Demyelinating XII motor axons, even transiently, would likely dramatically impair tongue motor control. More practical strategies 
may be to utilize multiple AAV injections and/or provide larger amounts of viral particles [73-76], or to utilize a more efficient retrograde vector. For example, a new rAAV variant (rAAV2-retro) has been created by directed evolution to increase the propensity for retrograde transport. While AAV2 and AAV9 showed similar labelling efficiency as rAAV2-retro at the site of injection, rAAV2-retro can enhance retrograde labelling by up to two orders of magnitude, at least in corticopontine projections [77]. The degree of labelling of rAAV2-retro rivals that of synthetic retrograde tracers within most neural systems tested and is consistently superior to other AAV serotypes [77].

\section{Targeting XII motoneurons via viral delivery directly to the XII nerve}

Since uptake of AAV requires binding to cell surface receptors [70, 71], direct delivery into the XII nerve using a needle or pipette may allow for increased uptake into axons. This was tested in a study of sciatic nerve vs. gastrocnemius delivery of AAV2 in mice, with nerve delivery infecting a greater proportion of motoneurons [78]. This has not been directly tested in the XII motor system, but on theoretical grounds direct nerve injection should increase efficacy. Proof-of-concept data shown in Fig. 3 illustrate that direct XII nerve injection with AAV9 can produce robust XII motoneuron transgene expression. Another consideration regarding nerve injection is that it should require considerably lower volumes as compared to intramuscular delivery [78], and this could lessen immune reactions. Following intramuscular AAV injections, transgene expression can be limited by immune-related abolition of viral particles, and/or cells expressing the transgene [79]. Particular challenges related to direct nerve delivery include the complexity of the XII nerve branching (e.g., Fig. 1) and the possibility for damage to the nerve due to the injection method. Nevertheless, an experienced surgeon will likely be able to isolate and microinject the main trunk of the XII nerve, or the prominent medial and lateral branches.

\section{Targeting XII motoneurons using stereotaxic brainstem delivery}

Delivery of gene transfer vectors into the medulla via stereotaxic injection is the most direct way to target XII motoneuron transduction [80-82]. For example, Horton et al. injected AAV8 to the XII nucleus using stereotaxic coordinates and histologically verified highly localized transgene expression in the XII nucleus [80]. Similar findings have been reported using AAV5 [81, 82]. Brainstem injections are unlikely to be clinically translatable due to surgical challenges and risks associated with inserting a needle into the medulla, but this approach enables proof-ofconcept preclinical studies. One limitation of direct intraparenchymal brainstem viral delivery is that it will be virtually impossible to uniquely target a specific muscle group (e.g., only genioglossus motoneurons), although it should be possible to target regions of the XII motor nucleus, such as dorsal vs. ventral.

\section{Tongue activation using chemogenetic and optogenetic approaches}

Designer Receptors Exclusively Activated by Designer Drugs (DREADD) technology has been utilized to directly manipulate XII motor output in at least four published studies [44, 80-82]. This approach uses selectively engineered muscarinic acetylcholine receptors that have been altered so that they no longer bind native ligands, but instead can be activated by select small molecules that are otherwise physiologically inert [83]. G-protein associated DREADDs can be utilized to stimulate, inhibit or silence the activity of cell populations [83]. Commonly, DREADD mediated excitation of neural circuits is achieved by expressing $\mathrm{Gq}$ signaling coupled muscarinic hM3Dq receptors in target neurons. These neurons can then be activated by systemic administration clozapine-N-oxide (CNO) [83] or related compounds [84] which act as ligands. Alternatively, neuronal inhibition can be achieved

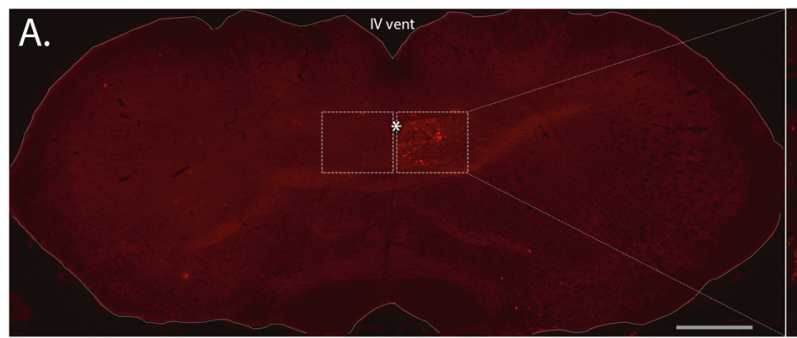

Fig. 3 Motoneuron transgene expression following direct delivery of AAV9-GFP to the XII nerve. A shows GFP expression visualized using a fluorescent secondary antibody. B GFP fluorescence in XII motoneuron soma. In both panels, the boxes show the approximate locations of the left and right XII nucleus and the * indicates the
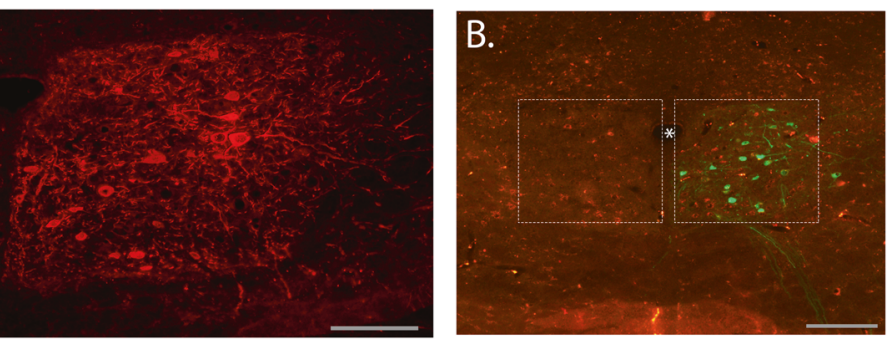

central canal. The images confirm XII motoneuron transgene expression is present ipsilateral to the AAV9 injection to the XII nerve. IV vent $=$ fourth ventricle. Scale bars: A left panel, $500 \mu \mathrm{m}$; right panel, $100 \mu \mathrm{m}$. B $250 \mu \mathrm{m}$ 
by expressing Gi signaling coupled muscarinic hM4Di receptors.

The first two descriptions of how expressing DREADDs in the XII nucleus could be used to activate the tongue were published almost simultaneously in 2017 [80, 81]. FleuryCurado et al. delivered an excitatory DREADD construct (rAAV5-hSyn-hM3(Gq)-mCherry) or a control virus (rAAV5-hSyn-EGFP) directly to the XII motor nucleus using stereotaxic surgery in C57BL/6J mice. Approximately 2 months later, delivery of the CNO ligand induced an increase in genioglossus muscle EMG activity accompanied by dilation of the pharyngeal airway as assessed using MRI. Horton et al. used a ChAT-Cre mouse model coupled with stereotaxic delivery of a cre-dependent vector (AAV8hSyn-DIO-hM3Dq-mCherry) to the XII motor nucleus. At 4 weeks post-AAV injection, CNO caused a sustained increase in tongue muscle EMG, but diaphragm EMG output was unaffected. The sustained increase in tongue motor activity was present during both non-REM and REM sleep. Together, these two seminal reports demonstrated that chemogenetics can be used to directly stimulate XII motoneurons with functional impact [80, 81].

A subsequent publication demonstrated that DREADDs can be used to inhibit XII motoneurons and thereby cause sleep disordered breathing [82]. An inhibitory construct was packaged in AAV5 (AAV5-hM4Di-mCherry) and delivered to the XII nucleus of C57BL/6J mice via direct stereotaxic injection. One month later, $\mathrm{CNO}$ administration caused airway obstruction during both REM and non-REM sleep. This work was supplemented with in vitro neurophysiology studies of brainstem slices in which direct intracellular recording confirmed that $\mathrm{CNO}$ caused a decrease in XII motoneuron bursting. A more recent publication has advanced the field by taking advantage of the capability for AAV9 to move retrogradely to target XII motoneurons following tongue injection [44]. Obese mice that display frequent upper airway obstruction during sleep were treated with an intralingual injection of AAV9 encoding an excitatory DREADD construct (AAV9-hSyn-hM3(Gq)mCherry). Histological studies confirmed that the virus effectively drove transgene expression in the XII motor nucleus, primarily in the ventromedial region containing genioglossus motoneurons. At 6-8 weeks following tongue injection, intraperitoneal delivery of a DREADD ligand caused a sixfold increase in genioglossus activity with concomitant increases in pharyngeal airway patency and increased airflow during non-REM sleep. DREADDinduced increases in genioglossus activity were not unique to inspiration, but rather occurred across the entire respiratory cycle. Two aspects of this work are particularly important for potential translation of chemogenetics in the context of sleep disordered breathing. First, the virus was delivered using direct tongue injection. This simple
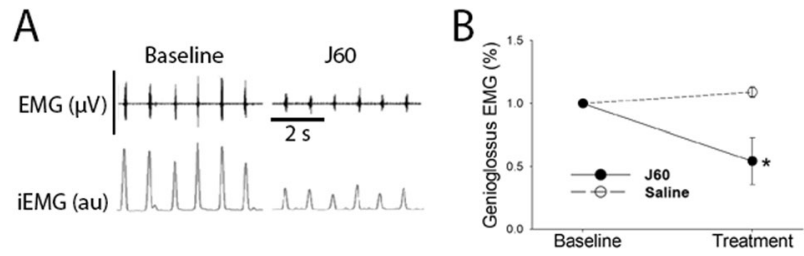

Fig. 4 Effect of JHU37160 dihydrochloride (J60) on genioglossal muscle activity in adult mice treated with intralingual injection of AAV9 encoding an inhibitory DREADD. Data were collected 8 weeks after intralingual injection with AAV9-HA-hM4D-mCherry. A Representative genioglossus muscle electromyography (EMG) activity recorded at baseline (left) and after administration of the DREADD ligand J60 (right). J60 was delivered via intraperitoneal (IP) injection at $0.1 \mathrm{mg} / \mathrm{kg}$ in $250 \mu \mathrm{l}$ saline. The top panel shows the raw EMG recording (scale bar $=40 \mu \mathrm{V}$ ) and the bottom trace shows the integrated signal (iEMG, arbitrary units, au). B Average inspiratory genioglossus EMG response to a single dose of J60 or saline $(n=7$, crossover design). Data are normalized to the peak phasic EMG amplitude at baseline. Inspiratory bursting showed a time $\times$ treatment statistical interaction $\left(F_{1,27}=46.3, P<0.001\right)$. *denotes a lower value in J60 vs. saline treated, $p<0.001$.

procedure [85] effectively transduced a sufficient number of XII motoneurons to enable a beneficial physiological response. Second, a novel DREADD ligand, JHU37160 [84] was used. The more commonly used CNO ligand has substantial off target effects, but JHU37160 can be delivered at much lower concentrations and has reduced risk of off target effects [84].

Figure 4 shows an example of DREADD-induced manipulation of genioglossus muscle EMG activity. These data from our research group were collected in C57BL/6J mice that had diet-induced obesity described in our recent publication [44]. At 6-8 weeks following tongue delivery of an AAV9 construct driving an inhibitory DREADD (AAV9-HA-hM4D-mCherry), intraperitoneal administration of the high potency DREADD ligand JHU37160 [84] $(0.1 \mathrm{mg} / \mathrm{kg})$ caused a marked decrease in genioglossus EMG activity. These data are consistent with the reports of retrograde targeting of XII motoneurons with AAV9 $[45,46,53]$ and confirm that viral-driven expression of inhibitory DREADDs be used to reduce XII motor output following intralingual AAV delivery.

Optogenetics is another approach producing rapid advances in neuroscience [86] and has the advantage of operating with high spatial and temporal resolution $[86,87]$. The first direct activation of XII motoneurons with optogenetics was recently published [88]. Transgenic mice expressing channelrhodopsin-2 (ChR2) only in cholinergic neurons (ChAT-ChR2(H134R)-EYFP) were studied in vivo under anesthesia. Photostimulation using a fiber-optic probe over the XII motor nucleus caused an immediate increase in tongue muscle EMG bursting proportional to the intensity of light stimulation. The response of the system was greater in non-REM sleep and wakefulness as compared to REM 
sleep [88]. Optogenetic stimulation can also effectively depolarize skeletal myofibers or motor axons, typically using ChR2. This potentially offers greater spatial and temporal precision as compared to direct electrical stimulation [89]. To our knowledge these techniques have not yet been applied to the tongue and/or XII nerve, and this represents a promising research opportunity.

Several groups have also used chemo- and optogenetic methods to stimulate excitatory or inhibitory presynaptic neural pathways to better understand the neural regulation of XII motoneuron activity [90-93]. For example, medullary $\mathrm{A} 1 / \mathrm{C} 1$ neurons were demonstrated to have an excitatory impact on XII motoneurons using a DREADD approach. A viral construct encoding an inhibitory DREADD (AAV10-hSyn-DIO-hM4Di-mCherry) was injected to the $\mathrm{A} 1 / \mathrm{C} 1$ region in $\mathrm{DBH}$-cre mice, and subsequent administration of CNO caused a decrease in genioglossus EMG output during NREM sleep [93]. Dergacheva et al. used optogenetics to explore the role of inhibitory neurons on tongue motor control [92]. Following stereotaxic delivery of AAV1-EF1a-DIO-hChR2 to the ventral medulla of GAD2-Cre mice, light activation caused inhibition of XII motor output. Interestingly, the inhibitory impact was greater for motoneurons innervating retractor vs. protrusor muscles. In the same study, in vivo chemogenetic activation of ventral medullary inhibitory neurons decreased tongue muscle EMG output. These studies illustrate the utility of chemo- and optogenetic techniques for studying the neural control of XII motoneurons, and potentially provide other neural substrates (e.g., beyond direct XII motoneuron stimulation) for therapeutic targeting.

\section{Conclusion}

Gene therapy targeting the XII motor system has therapeutic potential for a variety of lingual-related disorders, but this potential is largely untapped. The relative ease of access to the tongue for viral delivery facilitates targeted treatment of myopathy [45]. As the field moves forward, selectively targeting individual tongue muscles, and by retrograde viral movement, their motoneurons [44], may provide a means of optimizing tongue-related gene therapy for specific needs or conditions. On the other hand, in the case of genetic disorders, delivery of a therapeutic gene may not require such specificity, but rather targeting the entire XII motor system (e.g., protrusor and retractor muscles; intrinsic and extrinsic muscles) may be appropriate. Initial successes with chemogenetic methods for selective XII motoneuron stimulation raise new possibilities for treating OSA or other conditions [80, 81]. Optogenetics may also be useful in this regard, but little work has been done in that area. Similarly, to our knowledge neither opto- nor chemogenetics have been explored in preclinical studies aimed at dysphagia and dysarthria. For all studies of gene transfer in the XII motor system, preclinical or clinical, the biomechanical and anatomical complexity of the XII motor system, and in particular the different mechanical actions of tongue protrusor vs. retractor muscles are important considerations. The importance of tongue motor control to speaking, swallowing and breathing, and the prevalence of lingual-related disorders serve to underscore the need for further research in gene transfer to the XII motor system.

\section{Materials and methods}

This article contains original data included to illustrate concepts related to gene delivery to the XII motor system. Experimental protocols were approved by the Institutional Animal Care and Use Committees at the University of Florida (Figs. 2, 3) or Johns Hopkins University (Fig. 4). For the Fig. 2 data, a 3-month-old male 129SVE mouse received a unilateral injection to the base of the tongue with AAV9-CMV-GFP $\left(20 \mu \mathrm{L}\right.$; titer $\left.=1.20 \times 10^{13} \mathrm{vg} / \mathrm{mL}\right)$. The mouse was anesthetized using inhaled isoflurane and the virus was delivered to the base of the tongue as in our prior publications [44-46, 53]. Eight weeks later, the mouse was anesthetized with $3 \%$ isoflurane and systemically perfused with $0.9 \%$ saline followed by $4 \%$ paraformaldehyde. Tissues were harvested and placed in $4 \%$ paraformaldehyde for $24 \mathrm{~h}$ at $4{ }^{\circ} \mathrm{C}$ before sectioning using a cryostat $(10 \mu \mathrm{m})$. Expression of GFP was visualized using a DAB (3, 3-diaminobenzidine)-peroxidase reaction as in our prior publication [85]. The data in Fig. 2 have been replicated in four published reports [44-46, 53]. For the Fig. 3 data, a 2month-old male Sprague-Dawley rat received a $1.5 \mu \mathrm{L}$ injection of AAV9-CBA-GFP (titer $=1.86 \times 10^{13} \mathrm{vg} / \mathrm{ml}$ ) to the right XII nerve under $3 \%$ isoflurane anesthesia. Nerve injection was done using a pulled glass micropipette connected to a Hamilton syringe. The micropipette tip was inserted into the main XII nerve trunk, proximal to the bifurcation into medial and lateral branches (see Fig. 1). After 8 weeks, the animal was anesthetized and perfused as described above, and brainstem tissues were harvested and then cut $(40 \mu \mathrm{m})$ using a cryostat. Immunochemistry was performed using an antibody against GFP (Abcam; Rabbit polyclonal to GFP; lot: GR3271077) and a fluorescent secondary antibody as previously described [85]. Direct nerve injection with AAV has been demonstrated to drive motoneuron gene expression in other motor systems [78], but to our knowledge this is the first demonstration of this method in the XII motor system. To generate the Fig. 4 data, 3-4-month-old male $\mathrm{C} 57 \mathrm{BL} / 6 \mathrm{~J}$ mice received an intralingual injection of AAV9-HA-hM4D-mCherry (Gi) 
targeting the genioglossus muscle $\left(7 \times 10^{10} \mathrm{vg}, 10 \mu \mathrm{l}\right.$ in total) using the same methods described in our recent publication [44]. Mice were housed 4 or 5 per cage, in a temperature and humidity-controlled room with a $12 / 12$ light/dark cycle (9 a.m. -9 p.m. lights on; 9 p.m. -9 a.m. lights off) with free access to water. Mice were fed with high fat diet (TD 03584, Teklad WI, $5.4 \mathrm{kcal} / \mathrm{g}, 35.2 \%$ fat, $58.4 \% \mathrm{kcal}$ from fat) ad libitum. Eight weeks later after AAV9 injection, mice were anesthetized with 2-3\% inspired isoflurane and then maintained at $1-2 \%$ to keep breathing rate at 60 per min. Teflon-insulated wire hook electrodes (stainless steel, Teflon-coated, A-M Systems, Carlsborg, WA) were inserted in the genioglossus muscle at the base of the tongue; wires were sutured to the neck musculature to maintain placement. The electromyogram (EMG) signal was amplified, band-pass filtered (30-1000 $\mathrm{Hz}$, alternating-current preamplifier; model $\mathrm{P} 511 \mathrm{~K}$, Grass Instruments), and digitized at $1000 \mathrm{~Hz}$ (LabChart Pro 7, Version 7.2, ADInstruments, Dunedin, NZ). The EMG was rectified, and a $100 \mathrm{~ms}$ time constant was applied to compute the moving average (LabChart Pro 7). After baseline EMG recording, mice were treated with JHU37160 dihydrochloride (J60) $(0.1 \mathrm{mg} / \mathrm{kg}$ in $250 \mu \mathrm{l}$ saline i.p.) or vehicle (saline). A total of 7 mice were studied using a crossover design. The animals received either saline or J60 on different days ( 2 day interval between experiments, presentation order was arbitrarily selected). An a priori statistical power calculation was not performed, and the sample size was based on prior experience with this model [44]. The experimenter was blinded to the treatment during data collection. For quantitative analysis, the peak phasic (inspiratory) components were measured for 10 consecutive breaths at baseline and $15 \mathrm{~min}$ following $\mathrm{J} 60$ or saline injection. The EMG bursts were expressed as a percent of the average phasic inspiratory baseline output. A two way repeated measures analysis of variance was used to evaluate the response to saline or J60; values are reported as mean \pm 1 standard deviation. A $p$ value of $<0.05$ was considered statistically significant. The use of DREADDs to manipulate XII motoneuron activity has been replicated in several prior studies [44, 80-82].

Funding This work was supported by NIH grants 2R01HD05268211A1 (DDF and BJB) and OT2 OD023854 (DDF), NIH R01HL128970 (VYP), NIH R01HL138932 (VYP), and AHA 19CDA34660245 (TFC).

\section{Compliance with ethical standards}

Conflict of interest The authors declare that they have no conflict of interest.

Publisher's note Springer Nature remains neutral with regard to jurisdictional claims in published maps and institutional affiliations.
Open Access This article is licensed under a Creative Commons Attribution 4.0 International License, which permits use, sharing, adaptation, distribution and reproduction in any medium or format, as long as you give appropriate credit to the original author(s) and the source, provide a link to the Creative Commons license, and indicate if changes were made. The images or other third party material in this article are included in the article's Creative Commons license, unless indicated otherwise in a credit line to the material. If material is not included in the article's Creative Commons license and your intended use is not permitted by statutory regulation or exceeds the permitted use, you will need to obtain permission directly from the copyright holder. To view a copy of this license, visit http://creativecommons. org/licenses/by/4.0/.

\section{References}

1. Sanders I, Mu L. A three-dimensional atlas of human tongue muscles. Anat Rec. 2013;296:1102-14.

2. Fregosi RF, Ludlow CL. Activation of upper airway muscles during breathing and swallowing. J Appl Physiol. 2014;116:291-301.

3. Kier WM, Smith KK. Tongues, tentacles and trunks: the biomechanics of movement in muscular-hydrostats. Zool J Linn Soc. 1985;83:307-24.

4. Powell GL, Rice A, Bennett-Cross SJ, Fregosi RF. Respirationrelated discharge of hyoglossus muscle motor units in the rat. $\mathrm{J}$ Neurophysiol. 2014;111:361-8.

5. Fregosi RF, Fuller DD. Respiratory-related control of extrinsic tongue muscle activity. Respir Physiol. 1997;110:295-306.

6. Smith JC, Goldberg SJ, Shall MS. Phenotype and contractile properties of mammalian tongue muscles innervated by the hypoglossal nerve. Respir Physiol Neurobiol. 2005;147:253-62.

7. Mu L, Sanders I. Human tongue neuroanatomy: nerve supply and motor endplates. Clin Anat. 2010;23:777-91.

8. McClung JR, Goldberg SJ. Functional anatomy of the hypoglossal innervated muscles of the rat tongue: a model for elongation and protrusion of the mammalian tongue. Anat Rec. 2000;260:378-86.

9. Pilarski JQ, Leiter JC, Fregosi RF. Muscles of breathing: development, function, and patterns of activation. Compr Physiol. 2019;9:1025-80.

10. de Campos DE,JH, da Silva TH, Piazza JL, Kraether Neto L. Palatoglossus muscle neuroanatomy-a review. J Morphol Sci. 2012;29:123-4.

11. Fregosi RF. Respiratory related control of hypoglossal motoneurons-knowing what we do not know. Respir Physiol Neurobiol. 2011;179:43-7.

12. Gaige TA, Benner T, Wang R, Wedeen VJ, Gilbert RJ. Three dimensional myoarchitecture of the human tongue determined in vivo by diffusion tensor imaging with tractography. J Magn Reson Imaging. 2007;26:654-61.

13. McClung JR, Goldberg SJ. Organization of the hypoglossal motoneurons that innervate the horizontal and oblique components of the genioglossus muscle in the rat. Brain Res. 2002;950:321-4.

14. Gilliam EE, Goldberg SJ. Contractile properties of the tongue muscles: effects of hypoglossal nerve and extracellular motoneuron stimulation in rat. J Neurophysiol. 1995;74:547-55.

15. Wealing JC, Cholanian M, Flanigan EG, Levine RB, Fregosi RF. Diverse physiological properties of hypoglossal motoneurons innervating intrinsic and extrinsic tongue muscles. J Neurophysiol. 2019;122:2054-60.

16. Stierwalt JA, Youmans SR. Tongue measures in individuals with normal and impaired swallowing. Am J Speech Lang Pathol. 2007; 16:148-56. 
17. Miller AJ. Oral and pharyngeal reflexes in the mammalian nervous system: their diverse range in complexity and the pivotal role of the tongue. Crit Rev Oral Biol Med. 2002;13:409-25.

18. Abd-El-Malek S. Observations on the morphology of the human tongue. J Anat. 1939;73:201-10.3.

19. Bartlett RS, Thibeault SL. Insights into oropharyngeal dysphagia from administrative data and clinical registries: a literature review. Am J Speech Lang Pathol. 2018;27:868-83.

20. Palmer JB, Drennan JC, Baba M. Evaluation and treatment of swallowing impairments. Am Fam Physician. 2000;61:2453-62.

21. Dworkin JP, Culatta RA. Tongue strength: its relationship to tongue thrusting, open-bite, and articulatory proficiency. J Speech Hear Disord. 1980;45:277-82.

22. Jones HN, Crisp KD, Asrani P, Sloane R, Kishnani PS. Quantitative assessment of lingual strength in late-onset Pompe disease. Muscle \& Nerve. 2015;51:731-5.

23. Solomon NP, Makashay MJ, Helou LB, Clark HM. Neurogenic orofacial weakness and speech in adults with dysarthria. Am J Speech Lang Pathol. 2017;26:951-60.

24. Walshe M, Miller N. Living with acquired dysarthria: the speaker's perspective. Disabil Rehabil. 2011;33:195-203.

25. Yorkston KM. Treatment efficacy: dysarthria. J Speech Hear Res. 1996;39:S46-57.

26. Brady MC, Clark AM, Dickson S, Paton G, Barbour RS. The impact of stroke-related dysarthria on social participation and implications for rehabilitation. Disabil Rehabil. 2011;33:178-86.

27. Cantemir S, Laubert A. Diagnosis and treatment of dysphagia. HNO. 2017;65:347-56.

28. Brodsky MB, Mayfield EB, Gross RD. Clinical decision making in the ICU: dysphagia screening, assessment, and treatment. Semin Speech Lang. 2019;40:170-87.

29. Clark H, Lazarus C, Arvedson J, Schooling T, Frymark T. Evidence-based systematic review: effects of neuromuscular electrical stimulation on swallowing and neural activation. Am J Speech Lang Pathol. 2009;18:361-75.

30. Arvedson J, Clark H, Lazarus C, Schooling T, Frymark T. Evidence-based systematic review: effects of oral motor interventions on feeding and swallowing in preterm infants. Am $\mathbf{J}$ Speech Lang Pathol. 2010;19:321-40.

31. McCauley RJ, Strand E, Lof GL, Schooling T, Frymark T. Evidence-based systematic review: effects of nonspeech oral motor exercises on speech. Am J Speech Lang Pathol. 2009;18:343-60.

32. Lind LA, Andel EM, McCall AL, Dhindsa JS, Johnson KA, Stricklin OE, et al. Intralingual administration of AAVrh10-miR (SOD1) improves respiratory but not swallowing function in a superoxide dismutase- 1 mouse model of amyotrophic lateral sclerosis. Hum Gene Ther. 2020;31:828-38.

33. Remmers JE, deGroot WJ, Sauerland EK, Anch AM. Pathogenesis of upper airway occlusion during sleep. J Appl Physiol Respir Environ Exerc Physiol. 1978;44:931-8.

34. Fogel RB, Trinder J, White DP, Malhotra A, Raneri J, Schory K, et al. The effect of sleep onset on upper airway muscle activity in patients with sleep apnoea versus controls. J Physiol. 2005;564:549-62.

35. Chan E, Steenland HW, Liu H, Horner RL. Endogenous excitatory drive modulating respiratory muscle activity across sleep-wake states. Am J Respir Crit Care Med. 2006;174: 1264-73.

36. Grace KP, Hughes SW, Horner RL. Identification of the mechanism mediating genioglossus muscle suppression in REM sleep. Am J Respir Crit Care Med. 2013;187:311-9.

37. Fleury Curado T, Oliven A, Sennes LU, Polotsky VY, Eisele D, Schwartz AR. Neurostimulation treatment of OSA. Chest. 2018;154:1435-47.
38. Oliven R, Tov N, Odeh M, Gaitini L, Steinfeld U, Schwartz AR, et al. Interacting effects of genioglossus stimulation and mandibular advancement in sleep apnea. J Appl Physiol. 2009;106:1668-73.

39. Eisele DW, Smith PL, Alam DS, Schwartz AR. Direct hypoglossal nerve stimulation in obstructive sleep apnea. Arch Otolaryngol Head Neck Surg. 1997;123:57-61.

40. Strollo PJ Jr, Soose RJ, Maurer JT, de Vries N, Cornelius J, Froymovich $\mathrm{O}$, et al. Upper-airway stimulation for obstructive sleep apnea. N Engl J Med. 2014;370:139-49.

41. Taranto-Montemurro L, Messineo L, Azarbarzin A, Vena D, Hess LB, Calianese NA, et al. Effects of the combination of atomoxetine and oxybutynin on OSA endotypic traits. Chest. 2020;157:1626-36.

42. Taranto-Montemurro L, Messineo L, Sands SA, Azarbarzin A, Marques M, Edwards BA, et al. The Combination of atomoxetine and oxybutynin greatly reduces obstructive sleep apnea severity. a randomized, placebo-controlled, double-blind crossover trial. Am J Respir Crit Care Med. 2019;199:1267-76.

43. Taranto-Montemurro L, Sands SA, Edwards BA, Azarbarzin A, Marques M, de Melo C, et al. Desipramine improves upper airway collapsibility and reduces OSA severity in patients with minimal muscle compensation. Eur Respir J. 2016;48:1340-50.

44. Fleury Curado T, Pho H, Freire C, Amorim MR, Bonaventura J, Kim LJ, et al. Designer receptors exclusively activated by designer drugs approach to treatment of sleep-disordered breathing. Am J Respir Crit Care Med. 2021;203:102-10.

45. Doyle BM, Turner SMF, Sunshine MD, Doerfler PA, Poirier AE, Vaught LA, et al. AAV gene therapy utilizing glycosylationindependent lysosomal targeting tagged GAA in the hypoglossal motor system of pompe mice. Mol Ther Methods Clin Dev. 2019;15:194-203.

46. Elmallah MK, Falk DJ, Nayak S, Federico RA, Sandhu MS, Poirier A, et al. Sustained correction of motoneuron histopathology following intramuscular delivery of AAV in pompe mice. Mol Ther J Am Soc Gene Ther. 2014;22:702-12.

47. Keeler AM, Zieger M, Semple C, Pucci L, Veinbachs A, Brown $\mathrm{RH} \mathrm{Jr}$, et al. Intralingual and intrapleural AAV gene therapy prolongs survival in a SOD1 ALS mouse model. Mol Ther Methods Clin Dev. 2020;17:246-57.

48. Fuller DD, ElMallah MK, Smith BK, Corti M, Lawson LA, Falk DJ, et al. The respiratory neuromuscular system in Pompe disease. Respir Physiol Neurobiol. 2013;189:241-9.

49. Taruno A, Kashio M, Sun H, Kobayashi K, Sano H, Nambu A, et al. Adeno-associated virus-mediated gene transfer into taste cells in vivo. Chem Senses. 2017;42:69-78.

50. Taruno A, Kashio M. AAV-mediated gene delivery to taste cells of the tongue. Methods Mol Biol. 2019;1950:299-307.

51. Lerch TF, O'Donnell JK, Meyer NL, Xie Q, Taylor KA, Stagg SM, et al. Structure of AAV-DJ, a retargeted gene therapy vector: cryo-electron microscopy at 4.5 A resolution. Structure. 2012;20:1310-20.

52. Boisgerault F, Mingozzi F. The skeletal muscle environment and its role in immunity and tolerance to AAV vector-mediated gene transfer. Curr Gene Ther. 2015;15:381-94.

53. ElMallah MK, Falk DJ, Lane MA, Conlon TJ, Lee KZ, Shafi NI, et al. Retrograde gene delivery to hypoglossal motoneurons using adeno-associated virus serotype 9. Hum Gene Ther Methods. 2012;23:148-56.

54. Fitzpatrick Z, Leborgne C, Barbon E, Masat E, Ronzitti G, van Wittenberghe $\mathrm{L}$, et al. Influence of pre-existing anti-capsid neutralizing and binding antibodies on AAV vector transduction. Mol Ther Methods Clin Dev. 2018;9:119-29.

55. Herzog RW. Immune responses to AAV capsid: are mice not humans after all? Mol Ther J Am Soc Gene Ther. 2007;15:649-50. 
56. Mueller C, Gernoux G, Gruntman AM, Borel F, Reeves EP, Calcedo R, et al. 5 Year expression and neutrophil defect repair after gene therapy in alpha- 1 antitrypsin deficiency. Mol Ther $\mathbf{J}$ Am Soc Gene Ther. 2017;25:1387-94.

57. Perez BA, Shutterly A, Chan YK, Byrne BJ, Corti M. Management of neuroinflammatory responses to AAV-mediated gene therapies for neurodegenerative diseases. Brain Sci. 2020;10:119.

58. Ronzitti G, Gross DA, Mingozzi F. Human immune responses to adeno-associated virus (AAV) vectors. Front Immunol. 2020;11:670

59. Corti M, Liberati C, Smith BK, Lawson LA, Tuna IS, Conlon TJ, et al. Safety of intradiaphragmatic delivery of adeno-associated virus-mediated alpha-glucosidase (rAAV1-CMV-hGAA) gene therapy in children affected by pompe disease. Hum Gene Ther Clin Dev. 2017;28:208-18.

60. Kaspar BK, Lladó J, Sherkat N, Rothstein JD, Gage FH. Retrograde viral delivery of IGF-1 prolongs survival in a mouse ALS model. Science. 2003;301:839-42.

61. Towne C, Schneider BL, Kieran D, Redmond DE, Aebischer P. Efficient transduction of non-human primate motor neurons after intramuscular delivery of recombinant AAV serotype 6. Gene Ther. 2010;17:141-6.

62. Taymans JM, Vandenberghe LH, Haute CV, Thiry I, Deroose $\mathrm{CM}$, Mortelmans L, et al. Comparative analysis of adenoassociated viral vector serotypes $1,2,5,7$, and 8 in mouse brain. Hum Gene Ther. 2007;18:195-206.

63. Rothermel M, Brunert D, Zabawa C, Díaz-Quesada M, Wachowiak M. Transgene expression in target-defined neuron populations mediated by retrograde infection with adeno-associated viral vectors. J Neurosci. 2013;33:15195-206.

64. Kaspar BK, Erickson D, Schaffer D, Hinh L, Gage FH, Peterson DA. Targeted retrograde gene delivery for neuronal protection. Mol Ther J Am Soc Gene Ther. 2002;5:50-6.

65. Hollis ER, Kadoya K, Hirsch M, Samulski RJ, Tuszynski MH. Efficient retrograde neuronal transduction utilizing selfcomplementary AAV1. Mol Ther J Am Soc Gene Ther. 2008;16:296-301.

66. Castle MJ, Gershenson ZT, Giles AR, Holzbaur EL, Wolfe JH. Adeno-associated virus serotypes 1,8 , and 9 share conserved mechanisms for anterograde and retrograde axonal transport. Hum Gene Ther. 2014;25:705-20.

67. Sturrock RR. Stability of motor neuron and interneuron number in the hypoglossal nucleus of the ageing mouse brain. Anat Anz. 1991;173:113-6.

68. Clarkson AN, Talbot CL, Wang PY, MacLaughlin DT, Donahoe PK, McLennan IS. Müllerian inhibiting substance is anterogradely transported and does not attenuate avulsion-induced death of hypoglossal motor neurons. Exp Neurol. 2011;231:304-8.

69. Murlidharan G, Samulski RJ, Asokan A. Biology of adenoassociated viral vectors in the central nervous system. Front Mol Neurosci. 2014;7:76.

70. Huang LY, Halder S, Agbandje-McKenna M. Parvovirus glycan interactions. Curr Opin Virol. 2014;7:108-18.

71. Dudek AM, Pillay S, Puschnik AS, Nagamine CM, Cheng F, Qiu $\mathrm{J}$, et al. An alternate route for adeno-associated virus (AAV) entry independent of AAV receptor. J Virol. 2018;92:e02213-17.

72. Castle MJ, Perlson E, Holzbaur EL, Wolfe JH. Long-distance axonal transport of AAV9 is driven by dynein and kinesin- 2 and is trafficked in a highly motile Rab7-positive compartment. Mol Ther J Am Soc Gene Ther. 2014;22:554-66.

73. Hollis ER, Jamshidi P, Lorenzana AO, Lee JK, Gray SJ, Samulski $\mathrm{RJ}$, et al. Transient demyelination increases the efficiency of retrograde AAV transduction. Mol Ther J Am Soc Gene Ther. 2010;18:1496-500.
74. Chao H, Liu Y, Rabinowitz J, Li C, Samulski RJ, Walsh CE. Several $\log$ increase in therapeutic transgene delivery by distinct adeno-associated viral serotype vectors. Mol Ther J Am Soc Gene Ther. 2000;2:619-23.

75. Hauck B, Xiao W. Characterization of tissue tropism determinants of adeno-associated virus type 1. J Virol. 2003;77:2768-74.

76. Fortun J, Puzis R, Pearse DD, Gage FH, Bunge MB. Muscle injection of AAV-NT3 promotes anatomical reorganization of CST axons and improves behavioral outcome following SCI. J Neurotrauma. 2009;26:941-53.

77. Tervo DG, Hwang BY, Viswanathan S, Gaj T, Lavzin M, Ritola $\mathrm{KD}$, et al. A designer AAV variant permits efficient retrograde access to projection neurons. Neuron. 2016;92:372-82.

78. Wu R, Wang H, Xia X, Zhou H, Liu C, Castro M, et al. Nerve injection of viral vectors efficiently transfers transgenes into motor neurons and delivers RNAi therapy against ALS. Antioxid Redox Signal. 2009;11:1523-34.

79. Gernoux G, Wilson JM, Mueller C. Regulatory and exhausted T cell responses to AAV capsid. Hum Gene Ther. 2017;28:338-49.

80. Horton GA, Fraigne JJ, Torontali ZA, Snow MB, Lapierre JL, Liu $\mathrm{H}$, et al. Activation of the hypoglossal to tongue musculature motor pathway by remote control. Sci Rep. 2017;7:45860.

81. Fleury Curado T, Fishbein K, Pho H, Brennick M, Dergacheva O, Sennes LU, et al. Chemogenetic stimulation of the hypoglossal neurons improves upper airway patency. Sci Rep. 2017;7:44392.

82. Fleury Curado TA, Pho H, Dergacheva O, Berger S, Lee R, Freire $\mathrm{C}$, et al. Silencing of hypoglossal motoneurons leads to sleep disordered breathing in lean mice. Front Neurol. 2018;9:962.

83. Roth BL. DREADDs for neuroscientists. Neuron. 2016; 89:683-94.

84. Bonaventura J, Eldridge MAG, Hu F, Gomez JL, Sanchez-Soto M, Abramyan AM, et al. High-potency ligands for DREADD imaging and activation in rodents and monkeys. Nat Commun. 2019;10:4627.

85. ElMallah MK, Falk DJ, Lane MA, Conlon TJ, Lee KZ, Shafi NI, et al. Retrograde gene delivery to hypoglossal motoneurons using adeno-associated virus serotype 9. Hum Gene Ther Methods. 2012;23:148-56.

86. Duebel J, Marazova K, Sahel JA. Optogenetics. Curr Opin Ophthalmol. 2015;26:226-32.

87. Häusser M. Optogenetics: the age of light. Nat Methods. 2014;11:1012-4.

88. Aggarwal JA, Liu WY, Montandon G, Liu H, Hughes SW, Horner RL. Measurement and state-dependent modulation of hypoglossal motor excitability and responsivity in-vivo. Sci Rep. 2020;10:550.

89. Gundelach LA, Huser MA, Beutner D, Ruther P, Bruegmann T. Towards the clinical translation of optogenetic skeletal muscle stimulation. Pflugers Arch. 2020;472:527-45.

90. Zhu L, Chamberlin NL, Arrigoni E. Muscarinic inhibition of hypoglossal motoneurons: possible implications for upper airway muscle hypotonia during REM sleep. J Neurosci. 2019;39:7910-9.

91. Song G, Poon CS. alpha2-Adrenergic blockade rescues hypoglossal motor defense against obstructive sleep apnea. JCI Insight. 2017;2:e91456.

92. Dergacheva O, Fleury-Curado T, Polotsky VY, Kay M, Jain V, Mendelowitz D. GABA and glycine neurons from the ventral medullary region inhibit hypoglossal motoneurons. Sleep. 2020;43:zsz301.

93. Rukhadze I, Carballo NJ, Bandaru SS, Malhotra A, Fuller PM, Fenik VB. Catecholaminergic A1/C1 neurons contribute to the maintenance of upper airway muscle tone but may not participate in NREM sleep-related depression of these muscles. Respir Physiol Neurobiol. 2017;244:41-50. 